\title{
Percepção de Risco e Velocidade: A lei e os Motoristas
}

Risk perception and speeding: The law and the drivers

Iara Picchioni

Thielen,Maria Virgínia

Filomena Cremasco

Grassi, Diogo Picchioni

Soares,Ricardo Carlos

Hartmann,Aristeu

Mazuroski Júnior \&

Cristiano Moreno Baladón

Universidade

Federal do Paraná

Artigo baseado na tese de

doutoramento, financiado pela CAPES, na Universidade Federal de Santa Catarina SC. 


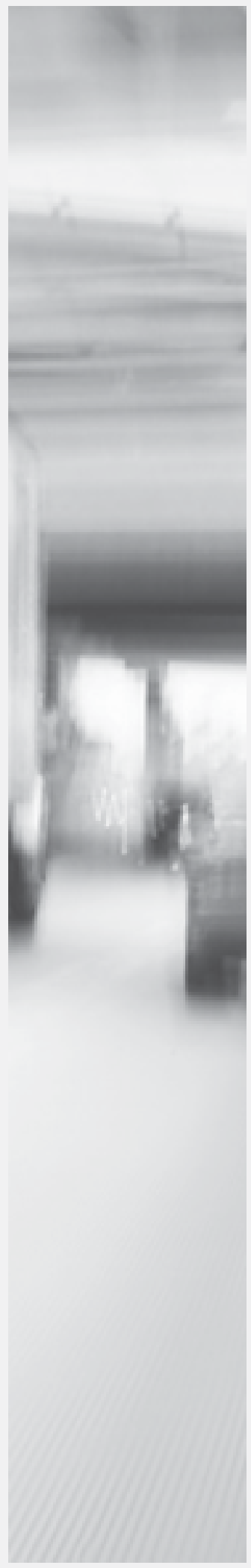

Resumo: Este artigo focaliza o excesso de velocidade no trânsito urbano e analisa o impacto da legislação sobre a percepção e o comportamento dos motoristas. O ponto de partida para a análise foram os textos legais sobre limites de velocidade: o Código de Trânsito Brasileiro de 1997, a legislação estadual, que modificou o enquadramento das vias no Paraná, e, em conseqüência, afetou as determinações relativas ao excesso de velocidade, e a Lei Federal de 2006, que modificou os limites de velocidade. Os textos legais apresentam ambivalências, que distorcem o conceito de limite e podem reforçar percepções inadequadas de que "correr moderadamente" não oferece risco. Isso se deve às constantes mudanças na legislação e à divulgação confusa, que permite que os motoristas reinterpretem a lei, identificando velocidades máximas conforme seu próprio entendimento. A placa de sinalização perde a função de estímulo discriminativo e torna-se incapaz de orientar um comportamento adequado e compatível com um trânsito seguro, o que potencializa os riscos. Recomenda-se que os textos legais sejam inequívocos, a fim de impedir outras interpretações, e fixem o limite único, a partir do qual todo excesso seja considerado gravíssimo.

Palavras-chave: subjetividade e trânsito, percepção de risco, excesso de velocidade.

Abstract: This paper deals with speeding in urban areas, surveying the law impact over the driver's perception and behavior. The starting point for the analysis was the legislation about speed limits: Brazilian Traffic Law, from 1997, the State legislation, that modified the streets classification, and consequently affected determinations about speeding, and the Federal Law, from 2006, that altered the infractions on speeding. The analysis of the Federal and State Law texts about driving over the speed limit shows the existence of ambiguities that cause distortions about the limit concept and may reinforce the inadequate perception that driving a little over the speed limit is not risky at all. This perception is motivated by frequent changes on the law text and its confusing advertising, that leads the drivers to misread the law and identify different speed limits. The traffic sign loses its discriminative stimulus sense and thus is unable to lead to a behavior both adequate and compatible with safe traffic, what increases the risk. The recommendation is to write clear texts that forbid double interpretation, fixing a single limit and making speeding to be considered a severe infraction.

Key words: subjectivity and traffic, risk perception, speeding. 


\section{Contexto desta análise}

Os estudos sobre a Psicologia do trânsito tradicionalmente incidiam sobre as atividades de habilitação de motoristas. Mais recentemente, houve uma ampliação dos focos de investigação, que incluem diversos outros aspectos relacionados ao comportamento humano no trânsito, entre eles, a percepção de riscos (Thielen, 2002; Wilde, 2005 ). A situação do trânsito demanda um conjunto de ações que possam promover a segurança de todos, e uma dessas ações enfoca os preceitos norteadores das condutas, que se expressam na legislação. Este ensaio toma como centro de análise o excesso de velocidade - estudado a partir de Curitiba, Paraná - estruturado em quatro aspectos: identificação dos textos legais que regulamentam o tema, explicitação das contradições dos textos legais, análise das decorrências das ambivalências dos textos legais sobre o indivíduo que deve tomar decisões a partir daquelas orientações e, finalmente, a apresentação de algumas recomendações.

\section{A lei e o comportamento humano}

A legislação é um produto social que pretende regular não só condutas individuais como também relações sociais. No trânsito, esperase que os motoristas conheçam e respeitem as leis de trânsito, que pedestres se comportem dentro de padrões esperados, que as sinalizações funcionem e auxiliem as relações entre pedestres e motoristas.

No entanto, a lei está situada no nível social. No nível individual, os comportamentos das pessoas se manifestam de forma a se aproximar ou se afastar das normas sociais, facilitando ou dificultando as interações entre pedestres, motoristas e agentes fiscalizadores. Ainda que o comportamento individual seja engendrado a partir das práticas sociais dos grupos nos quais o indivíduo está inserido, é possível encontrar diferentes comportamentos

e expectativas dentro de grupos aparentemente homogêneos. Espera-se, do ponto de vista social, que indivíduos que cumprem a lei contribuam para um trânsito mais harmônico; espera-se que os indivíduos respeitem a priori todos os pressupostos que nortearam as análises técnicas que resultaram em padronização de comportamentos. Esperase que os indivíduos, por exemplo, respeitem os limites de velocidade, uma vez que estudos técnicos foram realizados e orientaram as decisões contidas na legislação.

É possível identificar que uma parcela do conhecimento perito é utilizada pela legislação de trânsito ao definir limites de velocidade para determinadas vias. Ao mesmo tempo, destacase a importância exercida pela confiança nesses sistemas peritos, de modo que a legislação aparece como um mediador importante nos comportamentos sociais ao estabelecer normas que permitem uma convivência mais harmônica.

A norma, no entanto, não se transforma imediatamente em ação homogênea por parte dos integrantes da sociedade que estão sujeitos a ela. Cada indivíduo, cada grupo de pessoas sujeitos a determinada norma tem uma participação na forma como essa norma é veiculada, operacionalizada, percebida, respeitada, seguida, aprimorada, e essa interação é mediada pela percepção que os indivíduos e grupos têm da norma. Indivíduos e grupos diferentes percebem as normas de forma diferente, em função do contexto no qual estão inseridos. A percepção da norma vai orientar as decisões acerca do comportamento dos integrantes do trânsito de forma a aproximar-se ou afastar-se daquilo que seria desejável para a segurança de todos os integrantes.

O Código de Trânsito Brasileiro, de 1997 (Brasil, 1997), introduziu novos modelos de comportamento e modificou as relações entre os indivíduos e entre estes e o Estado, pelas 
novas regras de conduta preconizadas em seu texto. Como em todo processo de mudança, é necessário um período de adaptação para se efetivar ajustes. Conforme Cammi (1999, p. 11), “a prova de que uma lei é 'boa' é dada pela sua prática, e esta mesma trata de derrogar a 'lei má' por um estado de descumprimento generalizado, que termina por ser aceito por quem tem a obrigação de fazê-la cumprir".

Ao entender o comportamento do motorista como resultante da interação de inúmeros fatores, é possível destacar um deles e buscar sua relação com o ato de dirigir. Para fins deste ensaio, a legislação de trânsito e as normas específicas de velocidade foram os fatores selecionados, uma vez que o excesso de velocidade tem sido associado a acidentes (Abramet, 1999; French et al., 1993; Marin ; Queiroz, 2000; OMS, 1984).

\section{Textos legais que tratam de excesso de velocidade}

Há três textos legais que servem de base para a análise do excesso de velocidade e de suas decorrências para o comportamento do motorista: dois artigos do Código de Trânsito Brasileiro (CTB) - 61 e 218, uma Resolução do CETRAN-PR que subverte os preceitos do CTB e, finalmente, uma lei federal de 2006 que perverte ainda mais as diretrizes do CTB. O ponto de partida para analisar e compreender as variáveis envolvidas no comportamento de motoristas é a Lei $\mathrm{n}^{\circ} 9.503$, de 23 de setembro de 1997, que institui o Código de Trânsito Brasileiro (CTB), com vigência a partir de 22 de janeiro de 1998. Com esse novo código, abriu-se espaço para a municipalização do trânsito e definiu-se a nova estrutura e sinergia entre os níveis federal, estadual e municipal, que integram o Sistema Nacional de Trânsito.

O art. $5^{\circ}$ do CTB define o Sistema Nacional de Trânsito como o conjunto de órgãos e entidades da União, dos Estados, do Distrito Federal e dos Municípios cuja finalidade é o planejamento, administração, normatização, pesquisa, registro e licenciamento de veículos, formação, habilitação e reciclagem de condutores, educação, engenharia, operação do sistema viário, policiamento, fiscalização, julgamento de infrações e de recursos e aplicação de penalidades.

Segundo o art. $7^{\circ}$ do CTB, o Sistema Nacional de Trânsito é composto por:

"I - o Conselho Nacional de Trânsito CONTRAN, coordenador do Sistema e órgão máximo normativo e consultivo;

II - os Conselhos Estaduais de Trânsito CETRAN e o Conselho de Trânsito do Distrito Federal-CONTRANDIFE, órgãos normativos, consultivos e coordenadores;

III - os órgãos e entidades executivos de trânsito da União, dos Estados, do Distrito Federal e dos Municípios;

IV - os órgãos e entidades executivos rodoviários da União, dos Estados, do Distrito Federal e dos Municípios;

V - a Polícia Rodoviária Federal;

VI - as polícias militares dos Estados e do Distrito Federal e

VII - as Juntas Administrativas de Recursos de Infrações (JARI)."

O Conselho Nacional de Trânsito (CONTRAN) está regulamentado pelo Decreto $\mathrm{n}^{\circ} 2.327$, de 23 de setembro de 1997.

Atuam como órgãos normativos e consultivos nos Estados os Conselhos Estaduais de Trânsito (CETRAN), que, conforme o art. 14 do Código de Trânsito Brasileiro, têm, entre outras competências, "a elaboração de normas no âmbito das respectivas competências”.

Os órgãos executivos de trânsito atuam nos diversos níveis: o Departamento Nacional de Trânsito (DENATRAN), no nível federal; o Departamento Estadual de Trânsito (DETRAN), nos Estados, e, em Curitiba, a Diretoria de Trânsito (DIRETRAN), no nível municipal. 
Com esses diversos níveis de normatização e execução, constata-se a existência de regulamentações sobre os mesmos aspectos, porém com parâmetros definidos de forma diversa. É o caso dos limites de velocidade. O Código de Trânsito Brasileiro (CTB) apresenta no art. 61 três tipos de informações relativas à velocidade. Para melhor detalhamento, reproduz-se o texto:

“A velocidade máxima permitida para a via será indicada por meio de sinalização, obedecidas suas características técnicas e as condições de trânsito.

$\S 1^{\circ}$ Onde não existir sinalização regulamentadora, a velocidade máxima será de:

I - nas vias urbanas:

a) oitenta quilômetros por hora, nas vias de trânsito rápido;

b) sessenta quilômetros por hora, nas vias arteriais;

c) quarenta quilômetros por hora, nas vias coletoras;

d) trinta quilômetros por hora, nas vias locais. II - nas rodovias (...)

$\S 2^{\circ} \mathrm{O}$ órgão ou entidade de trânsito ou rodoviário com circunscrição sobre a via poderá regulamentar, por meio de sinalização, velocidades superiores ou inferiores àquelas estabelecidas no parágrafo anterior.”

É importante salientar as definições de vias, conforme o CTB:

VIA DE TRÂNSITO RÁPIDO - aquela caracterizada por acessos especiais com trânsito livre, sem interseções em nível, sem acessibilidade direta aos lotes lindeiros e sem travessia de pedestres em nível.

VIA ARTERIAL - aquela caracterizada por interseções em nível, geralmente controlada por semáforo, com acessibilidade aos lotes lindeiros e às vias secundárias e locais, possibilitando o trânsito entre as regiões da cidade.
VIA COLETORA - aquela destinada a coletar e distribuir o trânsito que tenha necessidade de entrar ou sair das vias de trânsito rápido ou arteriais, possibilitando o trânsito dentro das regiões da cidade.

VIA LOCAL - aquela caracterizada por interseções em nível não semaforizadas, destinada apenas ao acesso local ou a áreas restritas.

Que tipos de informações sobre limites de velocidade são constatados, a partir da leitura do CTB?

A primeira informação do art. 61 é que haverá placas indicativas de velocidade.

A segunda informação: na ausência de placas, valem as especificações $(80 \mathrm{~km} / \mathrm{h}, 60 \mathrm{~km} / \mathrm{h}$, $40 \mathrm{~km} / \mathrm{h}, 30 \mathrm{~km} / \mathrm{h})$.

A terceira informação é que órgãos com circunscrição sobre a via poderão regulamentar velocidades diferentes das especificadas.

Essas três informações incidem sobre o motorista, que deve responder com o comportamento adequado: dirigir na velocidade estabelecida. Mas o comportamento não é mecânico. Os diversos insumos são analisados e reinterpretados em função dos significados e valores que o motorista atribui a eles, ou dos significados veiculados pela norma.

Além das três informações contidas no art. 61, o art. 218 especificava (antes de ser modificado, em 2006) as regras para a aplicação de penalidades, tornando mais claros os preceitos dos limites de velocidade e definindo atribuição de gravidade em relação ao excesso, conforme o tipo de via.

No Capítulo XV do CTB, no art. 218, encontrase a indicação do tipo de infração e a respectiva penalidade quando se trata de excesso de velocidade. 
“Art. 218. Transitar em velocidade superior à máxima permitida para o local, medida por instrumento ou equipamento hábil:

I - em rodovias, vias de trânsito rápido e vias arteriais:

a) quando a velocidade for superior à máxima em até vinte por cento:

Infração - grave;

Penalidade - multa;

b) quando a velocidade for superior à máxima em mais de vinte por cento:

Infração - gravíssima;

Penalidade - multa (três vezes) e suspensão do direito de dirigir;

II - demais vias:

a) quando a velocidade for superior à máxima em até cinqüenta por cento:

Infração - grave;

Penalidade - multa;

b) quando a velocidade for superior à máxima em mais de 50\% (cinqüenta por cento):

Infração - gravíssima

Penalidade - multa (três vezes) e suspensão do direito de dirigir;

Medida administrativa - recolhimento do documento de habilitação.”

O texto da lei maior estabelecia que uma infração seria considerada grave ou gravíssima, com limites de velocidades diferentes conforme o tipo de via em que se transita, ou seja, para vias urbanas classificadas como arteriais ou de trânsito rápido, definiu-se que grave seria transitar em velocidades até $20 \%$ superiores à máxima permitida, e gravíssima, quando ultrapassasse os 20\%. Portanto, são utilizados dois critérios: porcentagens de acréscimos além do limite de velocidade e tipos de vias, o que facilmente leva à confusão, principalmente se for considerado que a classificação da via nem sempre é muito clara para o motorista, e, freqüentemente, nem para os técnicos da área, ou legisladores, já que o CETRAN-PR modificou o enquadramento das vias urbanas, conforme será explicitado.

Verificando os limites impostos no art. 61, as velocidades definidas pelo texto geral para vias arteriais ou de trânsito rápido são: $60 \mathrm{~km} / \mathrm{h}$ e $80 \mathrm{~km} / \mathrm{h}$. Também é importante salientar que o INMETRO estabelece $7 \mathrm{~km}$ como diferença de precisão em equipamentos de medição em relação aos velocímetros, e que o DENATRAN, através da Resolução $\mathrm{n}^{\circ} 02$, de 16 de janeiro de 2002, regulamentou esse valor, a ser considerado para todos os limites de velocidade estabelecidos: isso significava que o motorista que transitasse em até $79 \mathrm{~km} / \mathrm{h}$ (para uma velocidade máxima de $60 \mathrm{~km} / \mathrm{h}$, considera-se mais $7 \mathrm{~km}$, mais 20\%) ou até $103 \mathrm{~km} / \mathrm{h}$ (para uma velocidade máxima de $80 \mathrm{~km} / \mathrm{h}$, considera-se mais $7 \mathrm{~km}$, mais $20 \%$ ) estaria cometendo uma infração grave. Acima de $20 \%$, a infração era gravíssima, com suspensão da habilitação.

$\mathrm{O}$ art. 61 também estabelece as velocidades para as demais vias: coletoras, $40 \mathrm{~km} / \mathrm{h}$ e locais, $30 \mathrm{~km} / \mathrm{h}$, e, no inciso II, do art. 218 do CTB, estava explícita a regra: transitar em velocidades superiores à máxima em até 50\% era considerada infração grave, e, acima de 50\%, era gravíssima. Isso estava explícito ao considerar velocidades de $40 \mathrm{~km} / \mathrm{h}$ e $30 \mathrm{~km} / \mathrm{h}$, nas demais vias, significando, respectivamente, a definição de infrações para velocidades até $50 \%$, em $67 \mathrm{~km} / \mathrm{h}$ (para $40 \mathrm{~km} / \mathrm{h}$ ) e até $52 \mathrm{~km} / \mathrm{h}$ (para $30 \mathrm{~km} /$ h).

Qual o significado dessa regra, para o motorista? Curiosa e antagonicamente, significava que era possível manifestar o comportamento de exceder a velocidade de duas formas: 
“correndo mais” (50\%) em locais onde se deveria andar mais devagar (vias coletoras e vias locais), e “correndo menos” (20\%) onde se poderia andar mais depressa (vias arteriais e de trânsito rápido).

Isso sugeria a existência de uma concepção de excesso de velocidade que independia das condições de interação entre via, veículo e pessoas, uma concepção que determina que "correr moderadamente" (talvez até $67 \mathrm{~km} / \mathrm{h}$, num local onde a velocidade máxima permitida é de $40 \mathrm{~km} /$ h, ou $79 \mathrm{~km} / \mathrm{h}$, num local onde a velocidade máxima é de $60 \mathrm{~km} / \mathrm{h}$ ) não é perigoso. Tal fato corrobora a crença dos motoristas de que existem “excessos de velocidade” absolutos, sem correlação com interações.

O texto do CTB, dessa forma, orienta sobre os limites de velocidade considerando as vias e, ao mesmo tempo, indica que há excessos de velocidade independentes da via, mas o motorista deve tomar decisões e imprimir a velocidade adequada, orientada pela legislação. Ele teria que tomar essas decisões, que teriam repercussão em sua vida e na vida de terceiros, a partir de informações contraditórias.

No entanto, o mesmo artigo 61, no parágrafo segundo, permite que outros órgãos com circunscrição sobre a via definam parâmetros diversos. Foi o que ocorreu no Paraná: o CETRAN regulamentou, através da Resolução n 1515.0/2000, de 4 de outubro de 2000 (publicada em DOE em 19 de outubro de 2000): “Art. $1^{\circ}$ As penalidades por excesso de velocidade nas vias urbanas do Estado do Paraná serão enquadradas exclusivamente no inciso II, alínea 'a’ ou 'b’, do art. 218 do Código de Trânsito Brasileiro, conforme o excesso verificado”. Essa alteração se baseou na definição da categoria a que as vias urbanas do Estado do Paraná pertencem e modificou o enquadramento de “vias de trânsito rápido e vias arteriais” para “demais vias” - coletoras ou locais.

Embora essa Resolução do CETRAN/PR não altere o tipo de infração (grave ou gravíssima), modifica o intervalo do excesso de velocidade a ser considerado, já que o inciso I se refere a velocidades superiores à máxima em até 20\% e em mais de 20\% (que foi eliminado), e o inciso II se refere a velocidades superiores à máxima em até 50\% e em mais de 50\% (mantido como único critério). Conforme o CTB, a alínea “a”, tanto no inciso I como no II, refere-se à "infração grave, com multa de 120 UFIR, e perda de 5 pontos na carteira de habilitação”; a alínea "b”, em ambos os incisos, refere-se à "infração gravíssima, com multa de 540 UFIR, suspensão do direito de dirigir, e perda de 7 pontos na carteira de habilitação” (é importante lembrar que a referência à UFIR é do CTB, de 1997).

Tabela 1 - Tipos de vias, limites de velocidade e faixa para enquadramento de multas

\begin{tabular}{|l|l|l|l|l|l|l|}
\hline Via & Descrição & CTB & Limite & $20 \%$ & $50 \%$ \\
\hline Rápida & sem interseção/ sem acesso a lotes & 80 & até ou mais de $20 \%$ & 88 a 103 & a 127 \\
\hline Arterial & com interseção/ com acesso a lotes & 60 & até ou mais de $20 \%$ & 68 a 79 & a 97 \\
\hline Coletora & finalidade: entrar ou sair das & & & & & \\
\hline & vias anteriores & 40 & até ou mais de $50 \%$ & 48 a 55 & a 67 \\
\hline Local & interseção em nível sem semáforo & 30 & até ou mais de $50 \%$ & 38 a 43 & a 52 \\
\hline
\end{tabular}

A tabela 1 sintetiza as informações referentes aos tipos de vias, às velocidades máximas estipuladas pelo CTB e o enquadramento dos excessos conforme o CTB e conforme o CETRAN/PR, além de 
indicar os limites de $20 \%$ e $50 \%$, o que permite compará-los. Para uma velocidade máxima de $60 \mathrm{~km} / \mathrm{h}$, as determinações contidas no CTB explicitam as infrações: exceder em até 20\% corresponde a transitar em até $79 \mathrm{~km} / \mathrm{h}$, mas exceder em até 50\% (conforme resolução do CETRAN) significa que uma infração será grave se o motorista transitar em até $97 \mathrm{~km} / \mathrm{h}$. Somente haverá uma infração gravíssima se a velocidade for superior a $98 \mathrm{~km} / \mathrm{h}$. Isso significa aceitar uma velocidade próxima dos $100 \mathrm{~km} /$ h, numa via urbana, definida como "via coletora ou local” (velocidades definidas pelo CTB em 40 e $30 \mathrm{~km} / \mathrm{h}$ ), sem que haja, obrigatoriamente, a suspensão da habilitação (que ocorre quando a velocidade está acima de $98 \mathrm{~km} / \mathrm{h}$ ). Informações técnicas (Daros, 2004) estabelecem que um pedestre que for atropelado por um veículo que trafegue a $60 \mathrm{~km} / \mathrm{h}$ tem $70 \%$ de probabilidade de morrer e apenas 30\% de sobreviver (com seqüelas e mutilações). Determinou-se, no nível estadual, que, a partir de $98 \mathrm{~km} / \mathrm{h}$ é que se vai considerar que a infração seja gravíssima, o que contraria o bom senso, as estatísticas de mortalidade e o CTB.

Embora esse novo enquadramento sirva, de fato, para alterar de $20 \%$ para $50 \%$ a “tolerância”, e, em conseqüência, o enquadramento das multas correspondentes, o mesmo critério não foi usado para limitar a velocidade que "nas demais vias" seria de $30 \mathrm{~km} / \mathrm{h}$ e $40 \mathrm{~km} / \mathrm{h}$ - ainda que tudo seja muito contraditório.

Se as vias urbanas de Curitiba são classificadas (todas) em coletoras ou locais, como se justificam velocidades definidas num espectro tão amplo (de $30 \mathrm{~km} / \mathrm{h}$ a $70 \mathrm{~km} / \mathrm{h}$ ), de forma diferente do que preconiza o art. 61, para as “demais vias”? Como justificar, ainda, que, numa via classificada como coletora, se possa transitar a $70 \mathrm{~km} / \mathrm{h}$ ? Ou seja, para o enquadramento das vias, utilizou-se um tipo de critério (não explícito no texto da Resolução), e, para a definição do limite máximo de velocidade, não foram respeitadas as diretrizes contidas no CTB.

Assim, além das contradições internas do próprio CTB, em Curitiba, fica explicitada a falta de definição quanto à classificação das vias. Também se constata que a redução no valor das multas aplicadas, decorrentes do novo enquadramento, parece confundir ainda mais os motoristas ou beneficiar os infratores. No ano de 2006, a área de trânsito foi, mais uma vez, surpreendida pela legislação que comprometeu ainda mais a credibilidade dos integrantes do sistema. É importante a transcrição da Lei Federal no 11.334, de 25/ 07/2006, publicada no Diário Oficial da União de 26/07/2006, que dá nova redação ao art. 218 da Lei n ${ }^{\circ} 9.503$ (CTB), alterando os limites de velocidade para fins de enquadramentos infracionais e de penalidades.

Faço saber que o Congresso Nacional decreta e eu sanciono a seguinte Lei: Art. $1^{\circ} \mathrm{O}$ art. 218 da Lei $n^{\circ} 9.503$, de 23 de setembro de 1997, passa a vigorar com a seguinte redação:

“Art. 218. Transitar em velocidade superior à máxima permitida para o local, medida por instrumento ou equipamento hábil, em rodovias, vias de trânsito rápido, vias arteriais e demais vias:

I - quando a velocidade for superior à máxima em até 20\% (vinte por cento):

Infração - média;

Penalidade - multa;

II - quando a velocidade for superior à máxima em mais de $20 \%$ (vinte por cento) até $50 \%$ (cinqüenta por cento):

Infração - grave;

Penalidade - multa;

III - quando a velocidade for superior à máxima em mais de 50\% (cinqüenta por cento):

Infração - gravíssima; 
Penalidade - multa [3 (três) vezes], suspensão imediata do direito de dirigir e apreensão do documento de habilitação.” (NR)

Art. $2^{\circ}$ Esta Lei entra em vigor na data de sua publicação” (Lei Federal nº 11.334/2006).

Atualmente, com a nova redação, a infração por excesso de velocidade pode ser classificada em: média, grave e gravíssima.

O que analisar, então, após a Lei n 11.334, de 2006?

Dessa vez, a lei explicita um limite absoluto, independente do tipo de via. Reafirmando mais uma vez o equívoco quanto ao rigor com que deve ser tratado todo excesso de velocidade, a legislação fortalece a idéia de que o excesso de velocidade realmente não é perigoso. Isso contraria todas as informações referentes às principais causas dos acidentes: abuso de álcool e excesso de velocidade, e, principalmente, a associação dos dois (Marin; Queiroz, 2000). Com a nova Lei, considera-se que exceder a velocidade "um pouquinho”, ou seja, em 20\%, significa uma infração “média”. Para tornar ainda mais evidente o agravamento do equívoco, o quadro com os limites de velocidade deve ser refeito, considerando o mesmo limite de tolerância estabelecido pelo INMETRO, de $7 \mathrm{~km}$. A tabela 2 retrata as velocidades enquadradas como infrações médias, graves ou gravíssimas, para cada um dos limites estabelecidos conforme o tipo de via.

Tabela 2 - Tipos de vias, velocidades e enquadramento de multas após Lei 11.334

\begin{tabular}{|l|l|l|l|l|l|}
\hline Via & Descrição & CTB & $\begin{array}{l}\text { Média } \\
\text { até } 20 \%\end{array}$ & $\begin{array}{l}\text { Grave } \\
\text { de } 20 \% \text { até } 50 \%\end{array}$ & $\begin{array}{l}\text { Gravíssima } \\
\text { acima de } 50 \%\end{array}$ \\
\hline Rápida & $\begin{array}{l}\text { sem interseção/ sem } \\
\text { acesso a lotes }\end{array}$ & 80 & 88 a 103 & 104 a 127 & acima de 127 \\
\hline Arterial & $\begin{array}{l}\text { com interseção/ com } \\
\text { acesso a lotes }\end{array}$ & 60 & 68 a 79 & 80 a 97 & acima de 97 \\
\hline Coletora & $\begin{array}{l}\text { finalidade: entrar ou sair } \\
\text { das vias anteriores }\end{array}$ & 40 & 48 a 55 & 56 a 67 & acima de 67 \\
\hline Local & $\begin{array}{l}\text { interseção em nível } \\
\text { sem semáforo }\end{array}$ & 30 & 38 a 43 & 44 a 52 & acima de 52 \\
\hline
\end{tabular}

Pela nova lei, é possível exceder com o mesmo grau de gravidade os limites estabelecidos: há uma padronização. A contradição foi eliminada. Todas as vias são tratadas de forma equivalente quando o objetivo é fazer uma gradação nas infrações.

Os estudos indicam que todo excesso de velocidade é perigoso. Segundo Dotta e Dotta (2002, p. 16), "por medida de segurança, a maioria dos países da Comunidade Européia adota a velocidade de $50 \mathrm{~km} / \mathrm{h}$ nas vias prioritárias. Com essa velocidade, é possível evitar uma colisão ou atropelamento num espaço aproximado de 26 metros, enquanto a $60 \mathrm{~km} / \mathrm{h}$ seriam necessários aproximadamente 35 metros”. Se há um limite estabelecido, qualquer velocidade que exceda esse limite é gravíssimo. A nova lei, no entanto, diz aos motoristas que há um limite de velocidade em função das vias, mas ultrapassar esse limite pode representar três categorias de risco: médio, grave e gravíssimo.

Com a apresentação da legislação que regulamenta o excesso de velocidade, a partir da proposta original, contida no CTB, com seus detalhamentos, passando pela legislação no Paraná e, finalmente, 
com a alteração no nível federal das diretrizes contidas no CTB, é possível visualizar algumas contradições importantes. A partir dessa constatação, é possível analisar as conseqüências dessas constantes alterações nas bases definidoras do excesso de velocidade, do ponto de vista legal. Vale lembrar que, para o motorista, a legislação é sempre (ou deveria ser) o balizador do seu comportamento. As determinações para a obtenção da Carteira Nacional de Habilitação e para os processos de reciclagem de motoristas com habilitação suspensa focalizam a legislação como um dos principais aspectos a serem esclarecidos. Portanto, no comportamento dos integrantes do trânsito, e, principalmente, dos condutores de veículos, a legislação deveria ter uma dimensão significativa, já que é um instrumento importante, a partir do qual o motorista decide a velocidade que vai imprimir ao veículo, com todas as conseqüências daí advindas.

A partir dessas definições de limites de velocidade, a administração pública cria ou contrata mecanismos que possam verificar o cumprimento da lei. Um desses instrumentos é a fiscalização eletrônica, cuja implantação em Curitiba será tratada a seguir.

\section{Implantação da fiscalização eletrônica em Curitiba}

A Prefeitura Municipal de Curitiba determinou que implantaria medidas educativas cuja finalidade seria desenvolver nos motoristas novas formas de perceber e agir no trânsito, e que fossem adequadas ao novo Código de Trânsito Brasileiro (CTB). Essas medidas refletem a preocupação com o estabelecimento de um clima favorável à mudança de comportamento no trânsito, voltando-se para o período necessário de adaptação sempre que novos parâmetros são estabelecidos (novo código de trânsito). Uma dessas medidas refere-se especificamente ao art. 218 da Lei $n^{\circ}$ 9.503. A Prefeitura estabeleceu duas "notificações educativas”, ou seja, o motorista que cometia a infração "transitar em velocidade superior à máxima" não era multado na primeira vez, nem na segunda. Conforme aparece no "aviso" a Prefeitura informava que toleraria até duas situações dessa infração, e "somente na terceira vai valer a multa por excesso de velocidade". Além disso, incluía no "aviso" uma tabela que continha limites de velocidade, tipo de infração, multa e pontos. Esses avisos educativos permaneceram em vigência até a data de 30 de setembro de 2001. Concomitantemente, diversos folders educativos foram distribuídos à população, orientando o motorista em relação a diversos aspectos da condução de veículos, como velocidades e cuidados, entre outros.

\section{A fiscalização eletrônica}

No Brasil, existe um sistema de fiscalização eletrônica do excesso de velocidade que é "atualmente a maior e mais bem sucedida experiência de fiscalização eletrônica do mundo" (Cannell, 2001, p. 2). Segundo o autor, a fiscalização eletrônica reduz em 30\% o número de acidentes, e em $60 \%$ a mortalidade no trânsito.

Em Curitiba, constata-se redução significativa de acidentes após a implantação do sistema de fiscalização eletrônica. Na vias onde funcionam dez radares, nos oito meses antes da instalação, a média mensal de atropelamentos era de 4,6. Nos sete meses posteriores, a média baixou para 1,1. No período de janeiro a agosto de 1999, o total de atropelamentos nesses pontos foi de 37, ao passo que, no período de setembro de 1999 a fevereiro de 2000, foram registrados 7 atropelamentos. (Cannell, 2001, p.22).

Experiências com fiscalização eletrônica em outros países também indicam os benefícios que podem advir de uma implantação cuidadosa: no Uruguai, houve uma redução drástica no número de infratores (no trecho 
que liga Montevidéu a Punta del Este, no Município de Canelones): 55\%, comparandose fevereiro de 1999 (antes) e fevereiro de 2000 (depois); 71\%, comparando-se março de 1999 e março de 2000, e 87\%, comparando-se abril de 1999 e abril de 2000, o que resulta numa redução de $60 \%$ dos acidentes e na ausência de mortes no período de alta temporada (dezembro de 1999 a fevereiro de 2000). No Chile, um projetopiloto para controle de velocidade foi testado entre Santiago e o aeroporto, com o equipamento apenas avisando a velocidade, sem emissão de multa, e os resultados comparativos de três semanas antes e depois da implantação indicam uma redução na velocidade: "o volume de tráfego em excesso de velocidade (maior que $70 \mathrm{~km} / \mathrm{h}$ ), na faixa "lenta", foi reduzido de $41 \%$ para $23 \%$, e, na faixa "rápida", de 68\% para 36\%" (Cannell, 2001, p. 40). Em dez Estados americanos, o controle fotográfico no respeito ao sinal vermelho é permitido, e foi também utilizado em diversos países da Europa e África. Na Austrália, houve redução de 5,83 para 1,55 nos índices de acidentes, em onze meses de operação de fiscalização eletrônica implantada em abril de 1999 (Cannell, 2001).

Os procedimentos e modelos de conduta para atuar nas vias públicas permitem uniformizar comportamentos, de forma a torná-los percebidos, valorizados e previsíveis para todos, o que gera um clima de confiança, já que os integrantes do trânsito sabem o que devem fazer e o que se espera dos demais (Cammi, 1999). Esse clima de confiança pressupõe respeito pelo outro e pelas normas. Cammi (1999) é enfático ao afirmar que: "quando o sujeito desenvolve sistematicamente condutas arriscadas, transgressoras ou tendentes ao acidente, representa um problema objetivo e permanente de segurança viária, e, por isso, se torna um incapaz para o trânsito (...)"(p. 28), torna-se um risco. Pumpido (1963) ressalta: “(...) a periculosidade do sujeito inadequado para o tráfego se exterioriza geralmente antes que a sua atuação inadequada provoque um ato lesivo, na repetição de infrações das normas circulatórias e na adoção de posturas ou condutas que encerram um perigo potencial para os bem comportados” (p.65).

\section{Ambivalências da lei que incidem sobre a percepção de riscos}

O "espírito da lei" havia estabelecido uma diferença entre os excessos de velocidade ao classificar a infração em grave ou gravíssima, diferenciando as porcentagens do excesso (20\% - para velocidades mais altas ou 50\% para velocidades mais baixas), conforme o tipo de via.

Se, em frente a uma escola, o limite de velocidade determinado é de $30 \mathrm{~km} / \mathrm{h}$, o motorista agora sabe, a partir da Lei $\mathrm{n}^{\circ} 11.334$, que, se ele estiver transitando a $43 \mathrm{~km} / \mathrm{h}$, estará cometendo uma infração média; se estiver transitando de 44 a $52 \mathrm{~km} / \mathrm{h}$, a infração será grave, e a infração será gravíssima apenas se ele estiver transitando na saída de uma escola a mais de $52 \mathrm{~km} / \mathrm{h}$. Aos motoristas, pedestres e demais usuários, cabe perguntar: por que o limite de velocidade é de $30 \mathrm{~km} / \mathrm{h}$ ? Existem mesmo riscos nessa velocidade ou acima dela? Que diferença de risco determina essa gradação das infrações? Qual o significado da diferença entre $20 \%$ ou $50 \%$ para o motorista?

Com todas essas indagações e sem respostas consistentes, os motoristas se julgam aptos a decidir o que é excesso de velocidade, e essas concepções são individualizadas e individualistas, o que atesta que para eles o trânsito é um fenômeno privado (Thielen, 2002).

É a partir do insumo definidor da velocidade que o motorista pode orientar seu comportamento adequando-se às regras. Também é a partir dos resultados de seu 
comportamento que o motorista pode mantêlo ou modificá-lo: se a lei prevê punições para determinados comportamentos (como é o caso de exceder a velocidade permitida), essas punições e as condições em que elas ocorrem devem estar claras para o motorista, de forma a permitir uma compreensão inequívoca dos riscos “legais” a que se expõe. Também deve permitir a associação do comportamento com o resultado, nesse caso, a multa, fazendo com que essa associação possa orientar uma mudança de comportamento - não cometer infração. O insumo "limite de velocidade" pressupõe as conseqüências legais advindas de sua desobediência - multa média, grave ou gravíssima. Isso se refere apenas ao aspecto legal.

Para o motorista, essas informações significam que o excesso de velocidade é tolerado com maior margem, o que significa que "não é tão perigoso”, nem gravíssimo. Segundo Silcock et al. (1999), 85\% dos motoristas entrevistados admitem exceder a velocidade, embora reconheçam que é ilegal; esses pesquisadores identificaram um limite de velocidade interno que está "freqüentemente, mas não sempre, acima do limite divulgado” (p. 45). O equívoco e a aparente falta de razão na determinação do limite de velocidade específico geram o abuso. Uma legislação que corrobora a percepção de ausência de perigo no excesso de velocidade dificulta a aceitação dos limites de velocidade impostos, ou seja, estabelecer um limite máximo de velocidade que se torna “elástico” confunde todas as pessoas que têm que se submeter a ele. Cabe a elas questionar: há riscos? E a lei está dizendo que pode haver “um pouquinho de risco” (infração média), para o qual se estabeleceu um valor de multa, e outros valores para "excessos mais elevados”. Qual o significado de "limite”? Um limite “frouxo" (já era anteriormente flexível, e agora inclui mais a categoria do acréscimo de porcentagem e gravidade) orienta o comportamento seguro? Oferece segurança para os integrantes do trânsito?
A resposta deve ser não. Limite significa exatamente isto: algo que não se pode ultrapassar. Então, como orientar alguém para obedecer a limites se há uma desorientação que ensina em quanto burlar esse limite e qual o significado monetário? E por que a orientação não inclui os riscos para os pedestres principalmente, dessas diferentes gradações de velocidades que já ultrapassaram o limite definido? Aliás, por que definir limites se sua desobediência será considerada uma infração média?

Nos relatos das pessoas que coordenam o sistema estadual e municipal de trânsito, uma queixa freqüente se refere aos registros de excesso de velocidade aferidos (para uma velocidade máxima de $60 \mathrm{~km} / \mathrm{h}): 68 \mathrm{~km} / \mathrm{h}$, $69 \mathrm{~km} / \mathrm{h}, 70 \mathrm{~km} / \mathrm{h}, 71 \mathrm{~km} / \mathrm{h}$ e $72 \mathrm{~km} / \mathrm{h}$. Os motoristas queixosos afirmam que "isso não é excesso de velocidade”. Pelas declarações dos administradores do trânsito, são essas as velocidades nas quais se registra o maior volume de infrações (nas vias em que o limite de velocidade é $60 \mathrm{~km} / \mathrm{h}$ ). A variação do valor inicial a partir do qual a infração é registrada $(68 \mathrm{~km} / \mathrm{h}$ quando a velocidade máxima permitida é de $60 \mathrm{~km} / \mathrm{h}$ ) se deve a diferenças de precisão de equipamentos (velocímetros, radares, entre outros) e não a “10\% de tolerância”, como supõem alguns motoristas. Mas, como um dos insumos é a informação incorreta de " $10 \%$ de tolerância”, o motorista não se baliza pelo limite definido em lei. Além disso, as placas de sinalização (nas "vias rápidas”) em Curitiba traziam explícita a informação de que a multa seria grave a partir de $68 \mathrm{~km} / \mathrm{h}$, sugerindo ao motorista que o limite é $67 \mathrm{~km} / \mathrm{h}$, e não $60 \mathrm{~km} / \mathrm{h}$.

Ao invés de entender "tolerância” como uma salva-guarda contra disparidades de equipamentos de medição, o motorista entende que existirá tolerância sobre o quanto ele pode desrespeitar a lei. Com a nova lei, agora o motorista tem certeza e amparo legal para pensar assim e agir conforme essa 
distorção, imprimindo sempre uma velocidade acima daquela fixada como limite. $\mathrm{O}$ foco muda do equipamento para o comportamento.

Um dos principais insumos para o comportamento do motorista (informação contida nas placas e legislação regulamentadora do excesso de velocidade) aparece eivado de desvios em termos da concepção expressa no CTB, e deveria ser o balizador das decisões nos diversos níveis descentralizadores do Sistema Nacional de Trânsito. Para os legisladores brasileiros, sempre é possível “dar um jeitinho” e utilizar as próprias brechas que a lei faculta para adotar normas desviantes do "espírito da lei”: afinal, o próprio art. 61 determina que “o órgão ou entidade de trânsito ou rodoviário com circunscrição sobre a via poderá regulamentar, por meio de sinalização, velocidades superiores ou inferiores àquelas estabelecidas no parágrafo anterior”.

Com a nova lei, isso foi reafirmado, pois agora as infrações são padronizadas, independentemente do tipo de via a que se refere o excesso, para todas as vias: até 20\%; mais de $20 \%$ e até $50 \%$ mais de $50 \%$.

Essas gradações nas velocidades e as penalidades diferentes confirmam para o motorista que existem mais riscos e menos riscos, se não relativos a fatores humanos e materiais específicos, pelo menos em relação a multas diferentes (multas maiores ou menores), ainda que não se tenha alterado o valor inicial a partir do qual se registra a infração (68km/h). Quando o CETRAN-PR ampliou os limites, passando a considerar uma infração grave (para uma via onde a velocidade máxima é de $60 \mathrm{~km} / \mathrm{h})$, de até $79 \mathrm{~km} / \mathrm{h}$ (20\%) para até $97 \mathrm{~km} / \mathrm{h}(50 \%)$, criou-se uma faixa de velocidade (de $80 \mathrm{~km} / \mathrm{h}$ a $96 \mathrm{~km} / \mathrm{h}$ ) na qual o motorista não sabe diferenciar a potencialidade dos riscos, o que permite que ele equipare danos de $68 \mathrm{~km} / \mathrm{h}$ (início do registro de infrações) com danos provocados por um veículo que trafega a $97 \mathrm{~km} / \mathrm{h}$. Tal modificação contraria todas as informações técnicas disponíveis sobre os riscos embutidos em determinadas velocidades; por exemplo, a possibilidade de morte de um pedestre é de $5 \%$ quando o veículo trafega a $20 \mathrm{~km} / \mathrm{h}$, mas passa a ser de $45 \%$ se a velocidade é de 50 km/h (Almqvist, 1997).

A percepção do risco de atropelamento pode ser um importante insumo para o controle da velocidade. Por percepção de risco, entendese a forma como os leigos pensam sobre o risco, que inclui um conjunto de crenças e valores que dão significado a um acontecimento ameaçador (Lima, 1998; Pidgeon et al., 1992). Ao se considerar o comportamento um sistema, é possível identificar fatores externos (do meio ambiente) e internos (do próprio indivíduo) que contribuem para a organização das percepções frente aos riscos e que orientarão o comportamento de prevenção de acidentes. A legislação pertence ao grupo de fatores externos.

As pesquisas relativas à percepção de risco dão os indicadores para se investigar principalmente aspectos relacionados ao controle, à confiança, à consciência do risco, ao confronto entre o risco objetivo e o risco percebido, ao grau de familiaridade com o risco, à gravidade do risco, à extensão dos danos e à responsabilidade pela prevenção (Burton, 1972; Kates; Burton; White, 1978; Langer, 1975; Lima, 1989, 1995, 1998; Weinstein, 1981; White, 1974).

Um dos insumos relacionados especialmente à percepção que os motoristas têm do excesso de velocidade, do significado, dos riscos envolvidos, dos mecanismos utilizados para controle e fiscalização é a legislação que regulamenta a matéria, e é essa legislação que está permitindo que as percepções de risco sejam construídas a partir de uma falsa sensação de controle, de um excesso de confiança nas habilidades dos motoristas, já que “correr moderadamente” não é perigoso. 
Além disso, a legislação impede a tomada de consciência sobre os riscos advindos do excesso de velocidade ao permitir a classificação e a gradação de velocidades (e de multas diferentes) além do limite fixado. Gradações na determinação do excesso de velocidade não dão lugar a uma percepção de risco compatível com as indicações dos peritos. Mas, se a concepção sobre os riscos decorrentes do excesso de velocidade está equivocada (“foi só um pouquinho!”), a Psicologia do trânsito tem uma contribuição importante no esclarecimento dos danos que informações ambivalentes produzem nas pessoas.

As percepções de risco são construídas em função do grau de confiabilidade nas instituições responsáveis pela determinação e administração do risco, conforme afirma Short (1984). Em decorrência, as variáveis identificadas e as diferentes informações serão responsáveis pela construção de percepções de risco a partir das quais os motoristas dirigirão seus comportamentos de exceder ou não a velocidade máxima permitida. Se as instituições responsáveis pela determinação dos limites de velocidade não fornecem aos motoristas indicações precisas que possam orientar as percepções de risco compatíveis com as análises dos riscos de excesso de velocidade, como os motoristas poderão dirigir suas percepções de risco em consonância com essas análises?

Para o motorista, resta uma legislação ambivalente que sugere o experimento relatado por Pavlov (1970), que provocou a neurose experimental: dois estímulos muito semelhantes (próximos em termos de gradiente) aos quais o cão se via impedido de reagir adequadamente. $\mathrm{O}$ motorista se coloca em posição de questionar limites que não lhe cabe definir: afinal, qual a velocidade adequada nessa via? E por quê? Quem determina? Por que ontem era um limite de velocidade, e hoje é outro? É perigoso ou não transitar a 97km/ h em vias urbanas? Em que grau (é grave ou gravíssimo)? O que determina a gravidade? Por que, em Curitiba, nas “vias rápidas”, a velocidade máxima permitida é de $60 \mathrm{~km} / \mathrm{h}$ e há vias nas quais a velocidade é $70 \mathrm{~km} / \mathrm{h}$ ?

Agora, considera-se que exceder a velocidade máxima permitida pode representar também um perigo talvez "médio"?

Sem respostas a essas indagações, sem parâmetros seguros que norteiem seu comportamento em relação à velocidade, cada motorista se vê diante da alternativa de decidir ele mesmo que velocidade é adequada e em que lugar, correndo o risco de adotar comportamentos inadequados que possam resultar em danos humanos ou materiais. Além disso, a fiscalização eletrônica é vista de forma ambivalente pelos usuários. Os mesmos indivíduos que acolhem a fiscalização eletrônica em bancos e shoppings rejeitam-na no trânsito. A aceitação ou rejeição depende da percepção de quem é fiscalizado e de quem é protegido por essa fiscalização: em bancos e shoppings, a vigilância é aceita, pois o indivíduo compreende que ela existe para aumentar a sua segurança; no trânsito, entretanto, a vigilância é entendida como mecanismo gerador de receitas para os órgãos fiscalizadores ou como manobra política, fato que dificulta a aceitação da medida e sua obediência.

Quando a fiscalização incide sobre o indivíduo que dirige um veículo e, portanto, pode colocar em risco a segurança de outras pessoas, há rejeição por grupos de motoristas. O controle externo, no trânsito, não é visto como exercício de cidadania, do direito à locomoção segura de todos no espaço público, mas como invasão de privacidade ou como mecanismo de arrecadação.

A mobilidade urbana é impossível de ser pensada senão como espaço compartilhado, e, mesmo assim, as leis de trânsito, muitas vezes, não são vistas pelos cidadãos como garantia 
de liberdade de locomoção segura. Por outro lado, a análise dos textos das leis (federal e estadual) sobre excesso de velocidade assinala a existência de ambivalências que incidem sobre os motoristas e podem reforçar percepções ainda mais inadequadas de que “correr moderadamente” não oferece risco. Uma lei que garantisse o mínimo de ameaça para a locomoção das pessoas deveria ter o máximo de transparência quanto às restrições que impõe ao uso do espaço público. Assim, recomenda-se que os textos legais prezem pela clareza, fixando um limite único de velocidade a partir do qual todo excesso seja considerado gravíssimo. A relativização presente atualmente nas leis de trânsito atesta sua fragilidade em garantir a liberdade e a segurança dos cidadãos na mobilidade urbana. Além disso, uma concepção inequívoca de que o excesso de velocidade sempre representa um grande perigo, e, portanto, é sempre gravíssimo, poderia nortear a redação de textos legais mais precisos, que orientassem um comportamento seguro no que diz respeito à velocidade.

\section{Iara Picchioni Thielen}

Professora da Universidade Federal do Paraná - UFPR. Coordenadora do Núcleo de Psicologia do Trânsito. Doutora em Ciências Humanas.

\section{Maria Virgínia Filomena Cremasco Grassi}

Professora da Universidade Federal do Paraná - UFPR. Coordenadora do Núcleo de Estudos de Desenvolvimento Humano. Doutora em Ciências Médicas.

\section{Diogo Picchioni Soares}

Bolsista do Núcleo de Psicologia do Trânsito (NPT-UFPR).

Ricardo Carlos Hartmann

Psicólogo colaborador do NPT. Especializando em Cidades, Meio Ambiente e Políticas Públicas pela UFPR. Mestrando em Arquitetura e Urbanismo pela UFSC

\section{Aristeu Mazuroski Júnior}

Psicólogo colaborador do NPT. Mestrando em Letras - Lingüística pela UFPR.

\section{Cristiano Moreno Baladón}

Psicólogo colaborador do NPT. Especialista em Psicologia do Trabalho.

Iara Picchioni Thielen

Av. Visconde de Guarapuava, 1535, ap. 43

CEP 80060-060 Curitiba, PR. Telefones: (41) 3264-6058 e 9134- 9134

Homepage: www.npt.ufpr.br E-mail: iara.thielen@gmail.com 
ABRAMET -Associação Brasileira de Acidentes e Medicina de Tráfego. São Paulo, n. 31, p. 10-36, 1999.

ALMQVIST, S. O novo enfoque para segurança de trânsito na Suécia. Anais do $3^{\circ}$ Congresso Brasileiro de Acidentes e Medicina de Tráfego. Fortaleza: ABRAMET, 1997.p.184-185.

BRASIL, DENATRAN, LEIS. Código de Trânsito Brasileiro, Lei nº 9.503 , em 23 de setembro de 1997.

BRASIL, LEIS. Lei Federal n 11.334, de 25/07/2006, publicada no Diário Oficial da União em 26/07/2006.

BURTON, I. Cultural and personality variables in the perception of natural hazards. In: WOHLWILL; CARSON (eds.), Environment and the social sciences. Washington, D. C., American Psychological Association, 1972.

CAMMI, C. T. Conceito médico-legal de capacidade ou aptidão psicofísica de tráfego. Revista da ABRAMET - Associação Brasileira de Acidentes e Medicina de Tráfego, São Paulo, n. 31, p. 10-36, 1999.

CANNELL, A. E. R. Inovações na fiscalização do trânsito. In: CANNELL A. E. R.; GOLD, P.A. Reduzindo acidentes: o papel da fiscalização de trânsito e do treinamento de motorista. Washington, D.C., Banco Interamericano de Desenvolvimento, 2001. p.01-53.

DAROS, E. J. O risco de atropelamento. Trabalho apresentado no III Fórum Zero Acidente - gerenciamento de riscos para a prevenção de acidentes de transporte e trânsito. Porto Alegre, 27 de maio de 2004. Disponível em www.pedestre.org.br

DOTTA, A. J.; DOTTA, R. M. Acidentes de trânsito: como evitá-los! Porto Alegre: Ed. do autor, 2002.

FRENCH, D. J.; WEST, R. J.; ELANDER, J.;WILDING J. M. Decisionmaking style, driving style and self-reported involvement in road traffic accidents. Ergonomics, Loughborough, 36, p.627-644, 1993.

KATES, R. W.; BURTON, I.; WHITE. G F. The environment as hazard New York: Oxford University Press, 1978.

LANGER, E. J. The illusion of control. Journal of Personality and Socia Psychology, 32, p. 311-328, 1975.

LIMA, M. L. A percepção de riscos e perigos. Psicologia, Lisboa, vol. VII (3), p. 325-350, 1989.
Viver com o risco: abordagens da Psicologia social ambiental. Inforgeo, Lisboa, 9-10, p. 39-54, 1995

Factores sociais na percepção de riscos. Revista da Associação Portuguesa de Psicologia. Psicologia, Lisboa, vol.XII, n.1, p. $11-28,1998$.

MARIN,L.; QUEIROZ, M. S. A atualidade dos acidentes de trânsitona era da velocidade: uma visão geral. Cad. Saúde Pública, Rio de Janeiro, v. 16, n. 1, 2000. Disponível em: <http://www.scielo.br/ scielo.php? script =sci_art text \& pid=S 0102 311X2000000100002\&lng=pt\&nrm=iso>. Acesso em: 01 Abr 2007.

OMS (ORGANIZACIÓN MUNDIAL DE LA SALUD). Accidentes de tráfico en los países en desarrollo. Série de informes técnicos 703. OMS: Genebra, 1984

PARANÁ, CETRAN, RESOLUÇÕES. Resolução n 1516.0/2000, de 4 de outubro de 2000 .

PAVLOV, I. Obras escolhidas. São Paulo: HEMUS, 1970.

PUMPIDO, C. V Curso Internacional de Direito da circulação; conferências e comunicados. Chefatura Central de Tráfego. Centro Internacional de Estudos Jurídicos sobre a Circulação na Estrada. Madrid, 1963.

SHORT, J. F. The social fabric at risk: toward the social transformation of risk analysis. American Sociological Review, Ohio, v. 49, p. 711725, Dec.1984.

SILCOCK, R., SMITH, K., KNOX, D., \& BEURET, K. What limits speed? Factors that affect how fast we drive. Interim Report. AA Foundation for Road Safety Research, Hampshire, July 1999.

THIELEN, I. P. Percepções de motoristas sobre excesso de velocidade no trânsito de Curitiba - Paraná, Brasil. Tese (doutorado em Ciências Humanas) - Universidade Federal de Santa Catarina, Florianópolis, 2002.

WEINSTEIN, N. D. Unrealistic optimism about future life events. Journal of Personality and Social Psychology, Washington, DC, 39, p. 806-820, 1981.

WHITE, G F. Natural hazards: local, national, global. New York: Oxford University Press, 1974.

WILDE. G. O limite aceitável de risco: uma nova Psicologia sobre segurança e saúde. São Paulo: Casa do Psicólogo, 2005.
Referências 